\title{
Test of FBG sensors for monitoring high pressure pipes
}

\section{Antonio Paolozzi, Claudio Paris, Cristian Vendittozzi, Ferdinando Felli, Marialuisa Mongelli, et al.}

Antonio Paolozzi, Claudio Paris, Cristian Vendittozzi, Ferdinando Felli, Marialuisa Mongelli, Gerardo De Canio, Alessandro Colucci, Hiroshi Asanuma, "Test of FBG sensors for monitoring high pressure pipes," Proc. SPIE 10168, Sensors and Smart Structures Technologies for Civil, Mechanical, and Aerospace Systems 2017, 101681Q (12 April 2017); doi: $10.1117 / 12.2260474$ Health Monitoring, 2017, Portland, Oregon, United States 


\title{
Test of FBG sensors for monitoring high pressure pipes
}

\author{
Antonio Paolozzi ${ }^{\mathrm{a}, \mathrm{b}}$, Claudio Paris ${ }^{\mathrm{b}, \mathrm{a}}$, Cristian Vendittozzi ${ }^{\mathrm{c}}$, Ferdinando Felli ${ }^{\mathrm{d}}$, Marialuisa \\ Mongelli $^{\mathrm{e}}$, Gerardo De Canio ${ }^{\mathrm{e}}$, Alessandro Colucci ${ }^{\mathrm{e}}$, and Hiroshi Asanuma ${ }^{\mathrm{f}}$ \\ ${ }^{a}$ Scuola di Ingegneria Aerospaziale, Sapienza University of Rome, Rome, Italy \\ ${ }^{b}$ Museo Storico della Fisica e Centro Studi e Ricerche Enrico Fermi, Italy \\ ${ }^{\mathrm{C}}$ Universidade de Brasilia, Brasil \\ ${ }^{\mathrm{d}}$ Dipartimento di Ingegneria Chimica Materiali e Ambiente, Sapienza University of Rome, Italy \\ eENEA, Centro Ricerche Casaccia, Italy \\ ${ }^{\mathrm{f}}$ Chiba University, Japan
}

\begin{abstract}
Fibre Bragg Grating (FBG) sensors are increasingly being used on a wide range of civil, industrial and aerospace structures. The sensors are created inside optical fibres (usually standard telecommunication fibres); the optical fibres technology allows to install the sensors on structures working in harsh environments, since the materials are almost insensitive to corrosion, the monitoring system can be positioned far away from the sensors without sensible signal losses, and there is no risk of electric discharge. FBG sensors can be used to create strain gages, thermometers or accelerometers, depending on the coating on the grating, on the way the grating is fixed to the structure, and on the presence of an specifically designed interface that can act as a transducer. This paper describes a test of several different FBG sensors to monitor an high pressure pipe that feeds the hydraulic actuators of a 6 degrees-of-freedom shaking table at the ENEA Casaccia research centre. A bare FBG sensor and a copper coated FBG sensor have been glued on the pipe. A third sensor has been mounted on a special interface to amplify the vibrations; this last sensor can be placed on the steel pipe by a magnetic mounting system, that also allows the its removal. All the sensor are placed parallel to the axis of the pipe. The analysis of the data recorded when the shaking table is operated will allow to determine which kind of sensor is best suited for structural monitoring of high pressure pipelines.
\end{abstract}

Keywords: FBG sensors, optic fibers, pipelines, vibration monitoring

\section{INTRODUCTION}

Fiber Bragg Grating (FBG) sensors are increasingly being used for real-time structural health monitoring. The sensors are created inside optical fibres; usually standard telecommunication fibres (single mode SM 9/125 standard) are used, which allows reducing costs for wiring and operation, because standard tool for operating with the optical fibres can be used. The market for FBG sensor is increasing with the time, and FBG technology can be used to replace other sensing technology in an increasing number of applications. The advantages are many: the very low signal loss of the optical fibres allow positioning the monitoring system far away from the monitored structure; a number of sensors can be placed on a single fibre, reducing the number of cables needed for building a network of sensors; FBG sensors are immune to electromagnetic interferences and almost insensitive to corrosion, so that can be used in harsh environments and near power lines of electronic devices; there is no risk of electrical discharge from an optical fibre, so that FBG sensors are safe to use in places where fire hazard is a concern. Because of the small dimensions of optical fibres, FBG sensors can even be embedded inside the materials of the structures to be monitored, either polymeric composites or metallic alloys. ${ }^{1-3}$ The insensibility to electromagnetic interferences made possible using FBG sensors for monitoring in extreme environments, such as in particle physics experiments. ${ }^{4-6}$ Because of the resistance to corrosion, FBG sensors have been proposed and used for monitoring boats and structure in marine environment. ${ }^{7,8}$ FBG sensors exhibit a good long term stability

Further author information: (Send correspondence to Claudio Paris)

Antonio Paolozi: E-mail: antonio.paolozzi@uniroma1.it

Claudio Paris: E-mail: claudio.paris@centrofermi.it

Sensors and Smart Structures Technologies for Civil, Mechanical, and Aerospace Systems 2017,

edited by Jerome P. Lynch, Proc. of SPIE Vol. 10168, 101681Q · @ 2017 SPIE

CCC code: $0277-786 X / 17 / \$ 18 \cdot$ doi: $10.1117 / 12.2260474$

Proc. of SPIE Vol. 10168 101681Q-1 
and zero drift, that makes this technology a preferred choice for monitoring civil engineering structures ${ }^{9-13}$ and cultural heritage structures. ${ }^{14-16}$ The FBG sensor written on the fibre is sensitive to strain and temperature, so that can be directly used as a strain gage or a temperature sensor. By applying interfaces designed on purpose, FBG technology can be used to monitor also accelerations, pressure, displacements and vibrations. In particular, metal coatings can be applied to improve the sensitivity toward temperature. ${ }^{17,18}$

Pipelines are a type of infrastructure that is particularly suited for exploiting the advantages of FBG technology, since pipelines can be placed in corrosive environments, needs very long arrays of sensors, shall be continuously monitored for long time, and the monitoring system shall not pose an additional hazard in case pipelines are used for flammable liquid and gases. Pipelines are vulnerable to operational and environmental damages (corrosion, fatigue), geohazard risks (earthquakes, soil movements, landslides, floods), and man-made damages such as vandalisms and illegal spilling. FBG sensors have been already proposed and tested for monitoring strain, pressure, leakage and movements of pipelines. ${ }^{19-25}$

A system for detecting pipeline damages and in particular vandalism and oil stealing, based on the monitoring of vibrations, has been tested in laboratory and in an outdoor experiment on a section of pipeline. ${ }^{26,27}$ The vibration sensor proposed consists of a FBG sensors glued on a cantilevered interface specifically designed for the amplification of the vibration. In the previous works, the device was able to detect vibrations induced by drilling a pipe at different distances from the monitored point. In this paper the device is tested on a pipe containing pressurized oil, and is compared with other FBG sensors for assessing the improvement in vibration monitoring.

\section{EXPERIMENTAL SETUP}

The test has been performed at the SITEC (Sustainable Innovation Technology) laboratory, in the Casaccia Research Centre of ENEA (the Italian National Agency for New Technologies, Energy and Sustainable Economic Development). The lab is equipped with two high performance seismic tables for three axial seismic tests of structures. The larger, 6 degrees-of-freedom, $4 \mathrm{~m} \mathrm{x} 4 \mathrm{~m}$ table, can test structures up to 10 ton mass and $3 \mathrm{~g}$ acceleration applied at the Center of Gravity at $1 \mathrm{~m}$ from the base table. The FBG sensors have been applied on a pipe that feeds the pressurized fluid to the hydraulic actuators that move the table. The pipe is mechanically isolated from the actuators and from the seismic table. Three sensors have been applied to the pipe (Fig. 1):

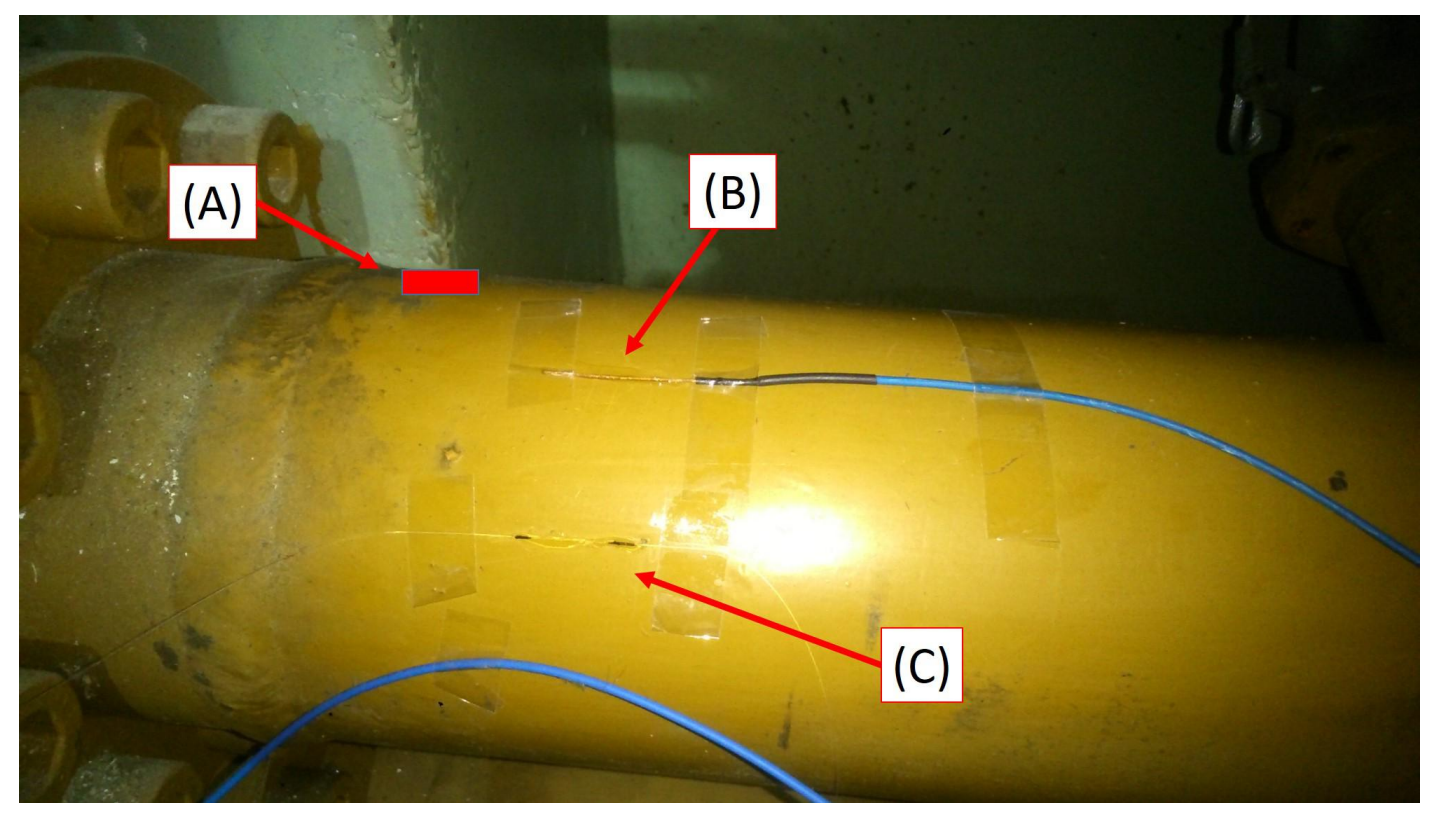

Figure 1. Positions of the FBG sensors on the monitored pipe. (A) is the position of the vibration sensor; (B) is the copper coated FBG sensor; (C) is the bare FBG sensor.

the vibration sensor, a copper coated FBG sensor and a bare FBG sensor. The copper coated and the bare 
FBG sensors have been glued to the pipe, while the vibration sensor is magnetic and is simply positioned on the steel pipe and can be easily removed. The copper coating on the second sensor was applied by the DICMA department of Sapienza University of Rome.

The sensors were fixed with the axis parallel to the pipe axis because the main target of the test was a comparison in the sensitivity to the vibration and not a measure of the deformation of the pipe under pressure. The FBG sensors were monitored using a Micron Optic sm130 interrogation system operated at $1 \mathrm{kHz}$ scan frequency. The pipe has a diameter of $16 \mathrm{~cm}$ and feeds high pressure hydraulic fluid to the actuators of the table. The pressure inside the pipe is $50 \mathrm{~atm}$ when the table is not operated, and reaches $200 \mathrm{~atm}$ during seismic tests. The temperature of the fluid starts from $30-35^{\circ} \mathrm{C}$ and reaches a maximum of $40^{\circ} \mathrm{C}$.

The sensors were monitored during a test of a structure. A typical seismic test is performed as follows:

- the structure is vibrated with a low-level sine-sweep excitation along each axis of the reference fram, for acquiring the resonance frequencies;

- the structure is vibrated with a simulated earthquake;

- the structure is, again, vibrated with a low-level sine-sweep excitation along each axis.

The resonance frequencies recorded after the first and the second sine-sweep tests are then compared to find damages from the simulated earthquake. The reference frame is such as that axis $\mathrm{X}$ and $\mathrm{Y}$ are in the horizontal plane, the axis $\mathrm{Z}$ is the vertical direction, perpendicular to $\mathrm{X}$ and $\mathrm{Y}$. However, the sensors are not placed on the table but on the feeding pipe, so the vibration recorded by the FBG sensors are not the frequencies of the table but are due mainly to the vibration from the servohydraulic sistems and the servovalves.

\section{PRELIMINARY DATA ANALYSIS}

In Fig. 2 are reported the data read during the sine-sweep along the $\mathrm{X}$-axis. The time domain plot shows that there is a wavelength shift on all the three sensors during the test. The shift is of $50 \mathrm{pm}$ on the bare FBG and $70 \mathrm{pm}$ on the vibration ("cantilever") sensor. In fact, FBG sensor have a thermal sensitivity of about $0.1^{\circ} / \mathrm{pm}$. Such a shift is compatible with a thermal wavelength shift from temperature increase of $5-7^{\circ} \mathrm{C}$, that is in the operational range expected from the system. Indeed, all the three sensors are recording not only the thermal effects on the Bragg grating but also the thermal expansion of the material on which are glued, that can amplify or lower the shift due to temperature. The two sensors directly glued on the pipe recorded a lower shift than the vibration sensor: probably the interface of the vibration sensor amplify the thermal effect because of the material used for its manufacturing. Such a shift was observed an all the sine-sweep tests.

Fig. 3 shows the frequency domain response of the FBG sensors during the same sine sweep test. The spectrum of the vibration sensor shows a strong response at $71.7 \mathrm{~Hz}$, which was not recorded by the copper coated sensor. The bare FBG sensor recorded both the $71.7 \mathrm{~Hz}$ frequency and another peak at $173.3 \mathrm{~Hz}$. Since the plots of the data in the time domain of the sine-sweep tests along $\mathrm{Y}$ and $\mathrm{Z}$ axis are very similar to the one of the test on $\mathrm{X}$ axis, in Fig. 4 and Fig. 5 are reported only the frequency domain responses.

In the Y-axis sine-sweep tests, both the coated FBG sensor and the bare sensor show two frequencies at 33.7 $\mathrm{Hz}$ and $71.7 \mathrm{~Hz}$, while the vibration sensor shows only the peak at $71.7 \mathrm{~Hz}$, but with a stronger amplitude.

The data from the simulated earthquake are reported in Fig. 6 (time domain) and Fig. 7 (frequency domain). In this last case, the frequency response of the bare FGB sensor shows two peaks at $29.0 \mathrm{~Hz}$ and $33.7 \mathrm{~Hz}$, plus the peaks at $71.7 \mathrm{~Hz}$ and $173.3 \mathrm{~Hz}$. The coated sensors shows only the peak at $29.0 \mathrm{~Hz}$, and the vibration sensor only the peak at $71.7 \mathrm{~Hz}$, with a larger amplitude than the bare sensor. 


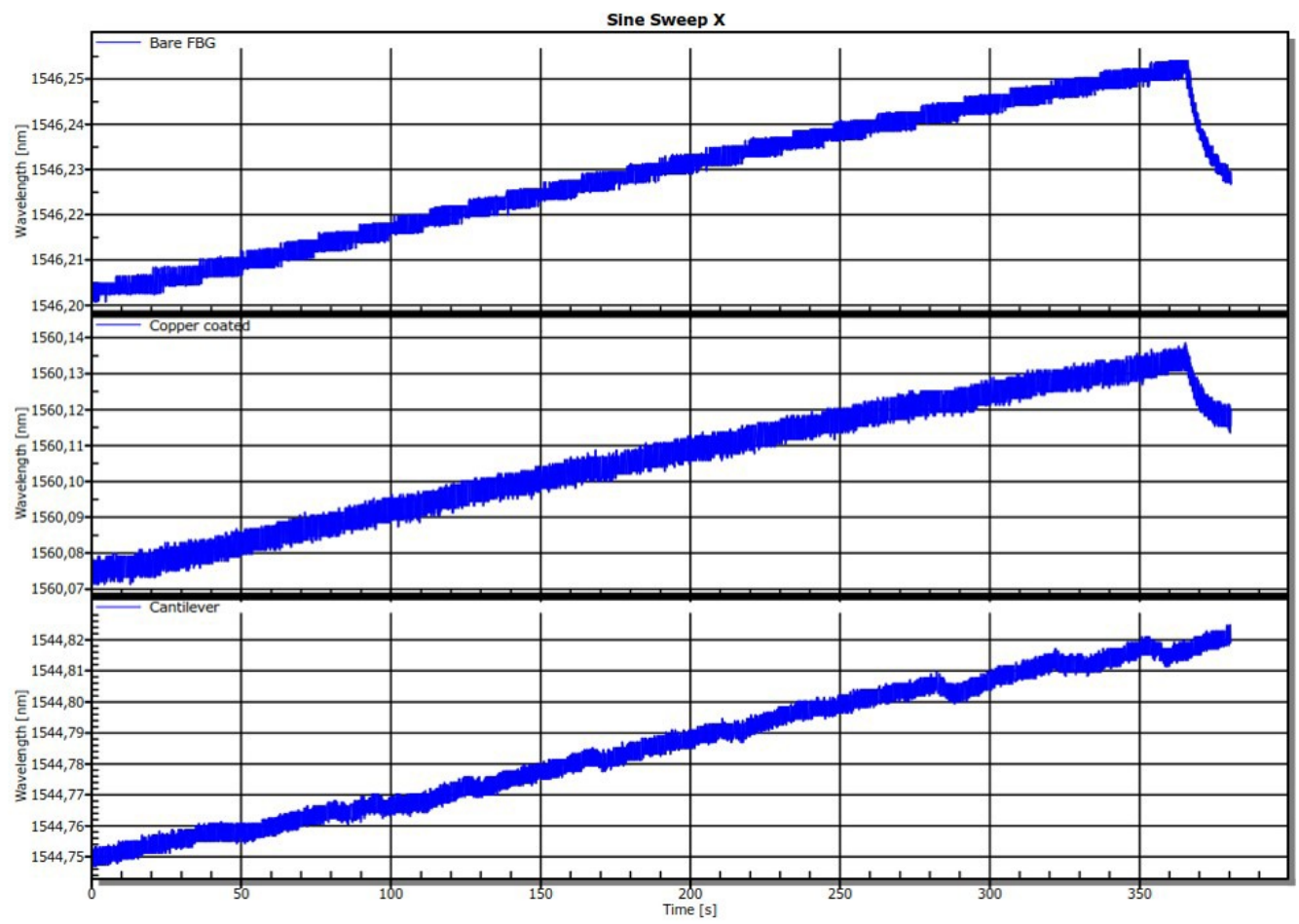

Figure 2. Data recorded during a sine-sweep test along the $\mathrm{X}$ axis of the table: time domain.

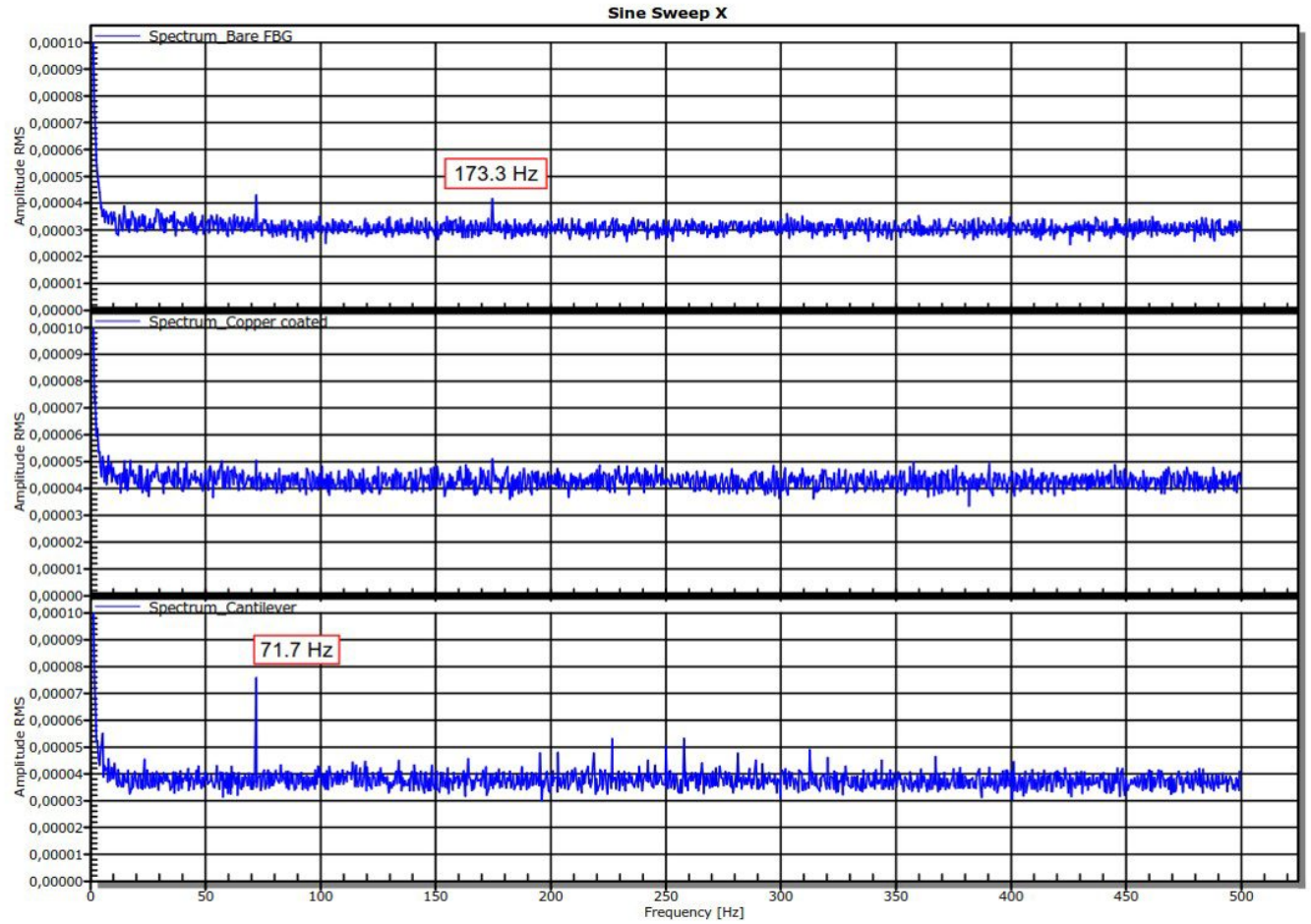

Figure 3. Data recorded during a sine-sweep test along the $\mathrm{X}$ axis of the table: frequency domain. 
Sine Sweep $Y$

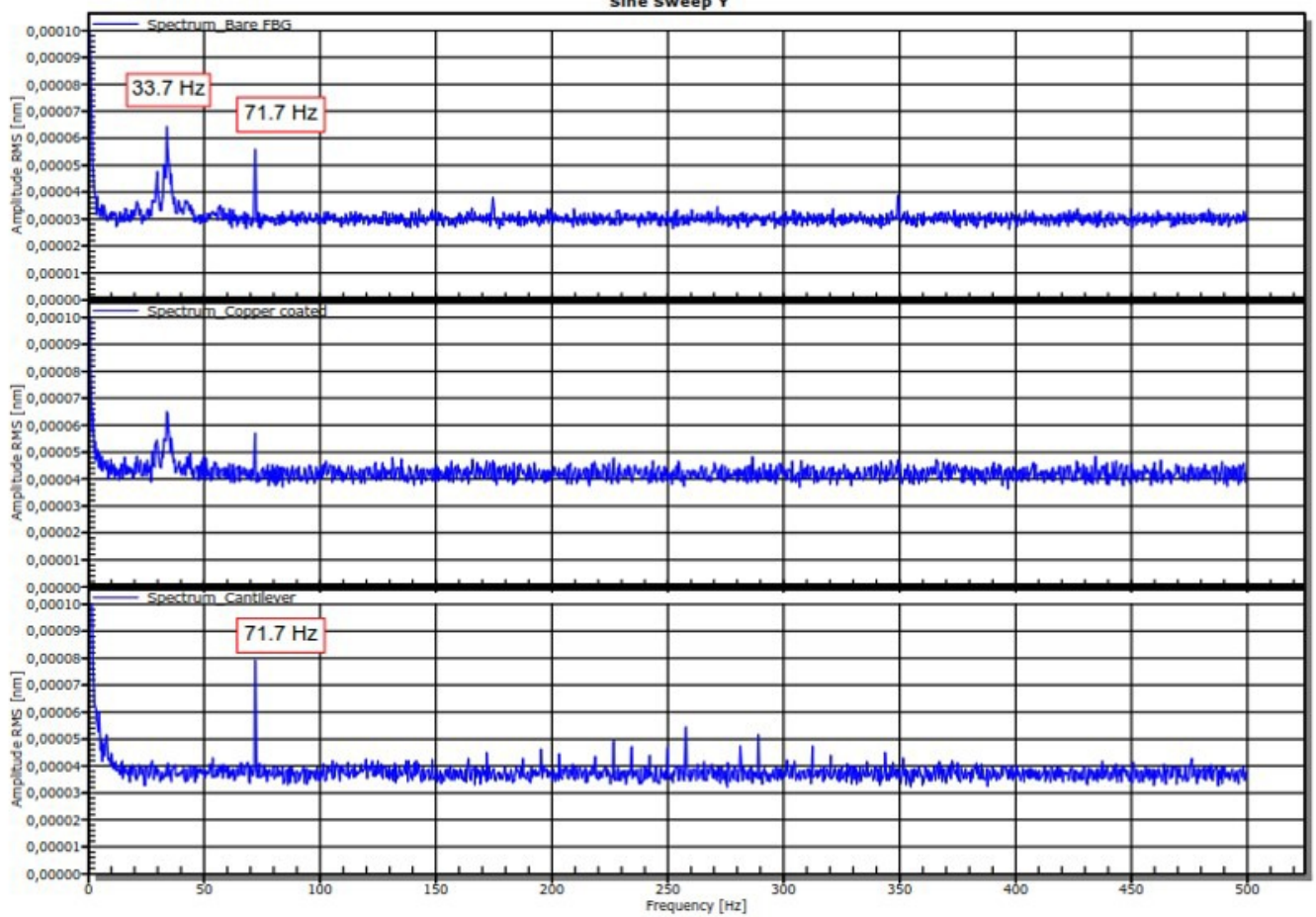

Figure 4. Data recorded during a sine-sweep test along the $\mathrm{X}$ axis of the table: frequency domain.

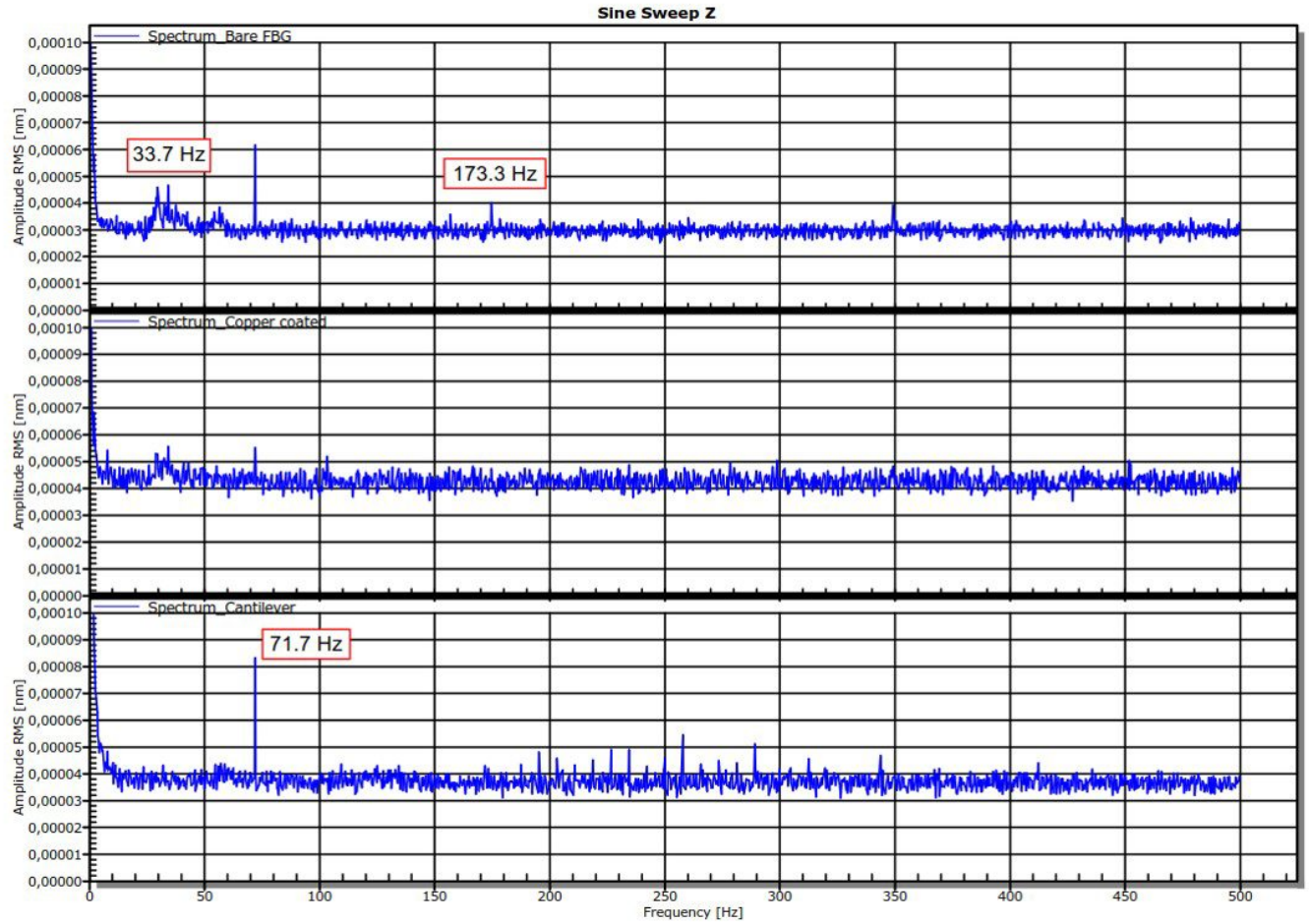

Figure 5. Data recorded during a sine-sweep test along the $\mathrm{Z}$ axis of the table: frequency domain. 


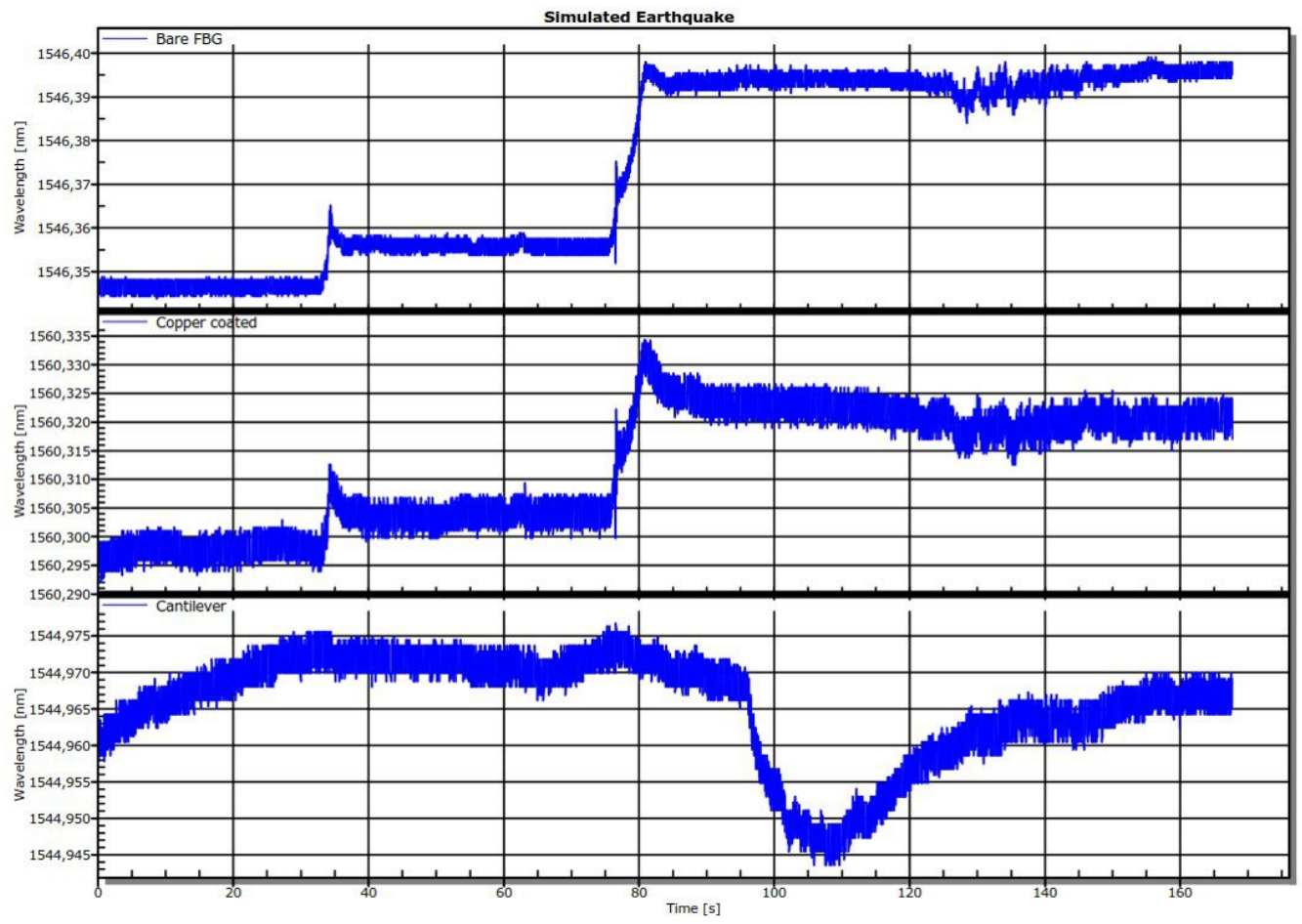

Figure 6. Data recorded during a simulated earthquake test: time domain.

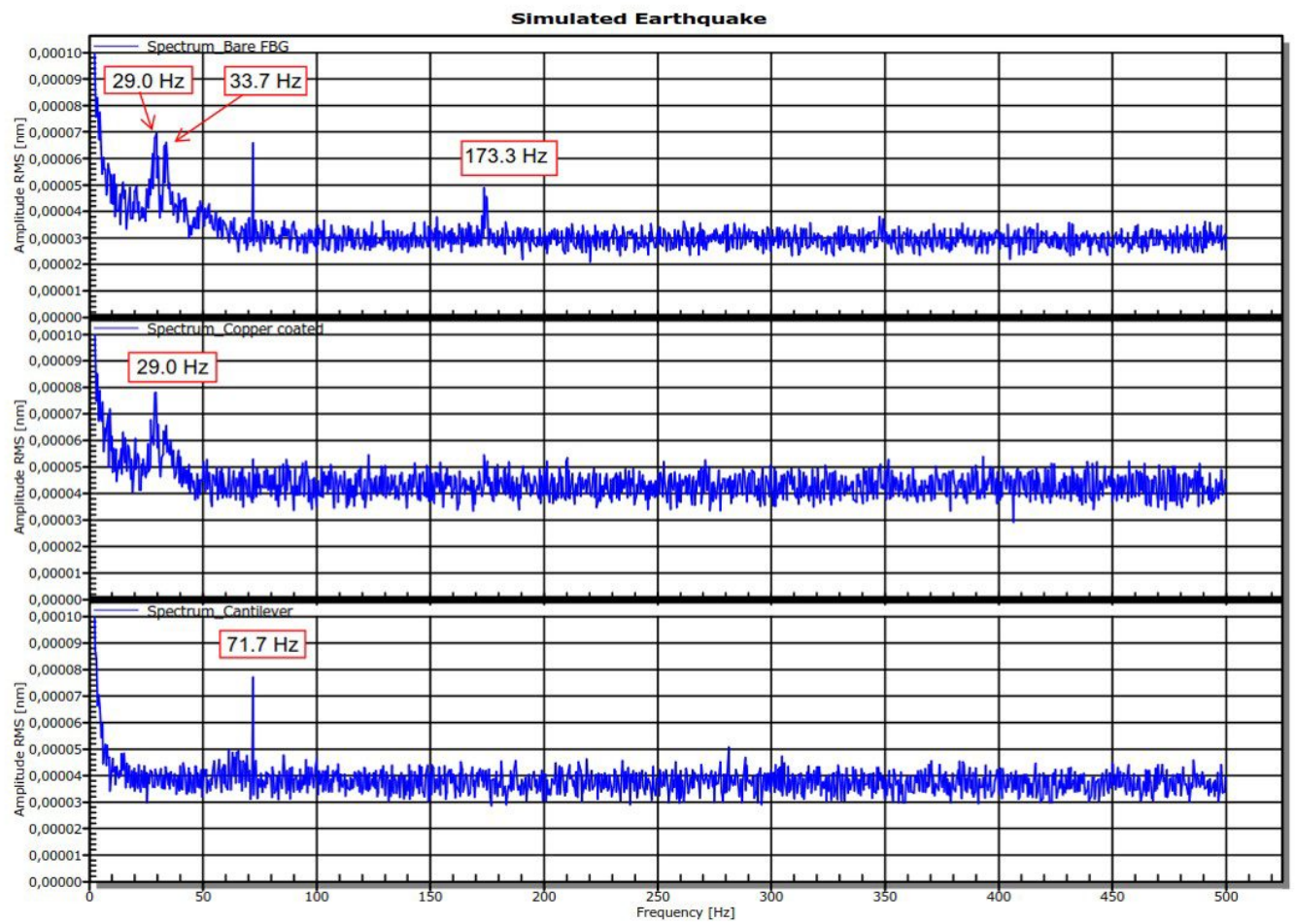

Figure 7. Data recorded during a simulated earthquake test: frequency domain. 


\subsection{Discussion of the results and future activities}

The sensor with the interface for vibration amplification managed to identify and to amplify only a frequency at $71.7 \mathrm{~Hz}$. The same frequency was identified by the other two sensors glued on the pipe, so it correspond to a real frequency on the pipe, probably due to some mechanical device for controlling the flow of the pressurized hydraulic fluid. However, the vibration sensor failed to identify the peaks at $29.0 \mathrm{~Hz}$ and $33.7 \mathrm{~Hz}$, that were seen by the bare sensor and the coated sensors, and the peak at $173.3 \mathrm{~Hz}$ seen by the bare sensor. In Ref. 28 the vibration sensor was applied to an empty pipeline and demonstrated that could identify frequencies of more than $90 \mathrm{~Hz}$, in particular the frequency of $150 \mathrm{~Hz}$ due to an attempt of perforation of the pipe with an electric drill tool. It is unclear why in this case it failed to record the $173.3 \mathrm{~Hz}$ frequency, while it is possible that the design can not detect and amplify frequencies lower than $70 \mathrm{~Hz}$ (like the one at $33.7 \mathrm{~Hz}$ ).

The coated sensor was the less responsive of the three. Future activities will further investigate the behaviour of the FBG sensors applied to a pipe under pressure, and the design of the vibration sensor will be modified to improve its response to a wider range of frequencies.

Future planned activities are:

- installing one FBG sensor on the circumference of the pipe, to measure the deformation due to pressure;

- installing one thermal FBG sensor to measure the temperature and to perform an analysis of the wavelength shift due to temperature;

- testing modified design of the vibration sensor, to improve its response to a wider range of frequencies.

\subsection{CONCLUSION}

This work reported the preliminary results of some tests of FBG sensors with different interfaces, applied to a pipe for hydraulic fluid under high pressure. The hydraulic fluid is used for operating a shaking table for seismic simulations and dynamic analysis of structures. One of the interfaces has been designed to amplify and detect vibration; it has already been tested on an empty pipe. The results showed that the vibration sensor can identify vibration from $70 \mathrm{~Hz}$ to $150 \mathrm{~Hz}$, but failed to amplify lower and higher frequencies, which were recorded by a bare FBG sensor glued on the pipe. The copper coating applied to another sensor did not improve its sensitivity toward vibrations. Future activities are planned to test a modified design of the vibration sensor and to test an FBG setup usable for monitoring pipes that transports fluids under pressure.

\section{ACKNOWLEDGMENTS}

The authors acknowledge the ENEA Casaccia Research Centre for the support to the test activities.

\section{REFERENCES}

[1] Paris, C., Vendittozzi, C., and Basaglia, M., "Experimentation of fiber optic fbf sensors in a cfrp aerospace component," in [22nd AIDAA conference], (September 2013).

[2] Paolozzi, A., Caponero, M. A., Cassese, F., and Leonardi, M., "Use of embedded optical bers for structural analysis," in [XVII International Modal Analysis Conference (IMAC)], 1, 699-704 (February 2001).

[3] Caponero, M., Felli, F., and Paolozzi, A., "Strain maesurement with fbgs embedded into cast metal alloys," in [The Seventh Japan International SAMPE Symposium. Information and innovation in composites technologies], T. Ishikawa, S. S., ed., 1, 661-664 (Nov 2001).

[4] Benussi, L., Bertani, M., Bianco, S., Caponero, M. A., Fabbri, F., Felli, F., Giardoni, M., Monaca, A. L., Pace, E., Pallotta, M., and Paolozzi, A., "Use of fiber bragg gratings sensors for position monitoring in high energy physics experiment BTeV," in [IEEE Sensor 2002], 874-879 (June 2002).

[5] Benussi, L., Bianco, S., Colafranceschi, S., Colonna, D., Daniello, L., Fabbri, F., Giardoni, M., Ortenzi, B., Paolozzi, A., Passamonti, L., et al., "The cms rpc gas gain monitoring system: an overview and preliminary results," Nuclear Instruments and Methods in Physics Research Section A: Accelerators, Spectrometers, Detectors and Associated Equipment 602(3), 805-808 (2009). 
[6] Bianco, S., "Gas analysis and monitoring systems for the rpc detector of cms at lhc," in [2006 IEEE Nuclear Science Symposium Conference Record], 2, 891-894 (October 2006).

[7] Mihailov, S. J., "Fiber bragg grating sensors for harsh environments," Sensors 12(2), 1898-1918 (2012).

[8] Vendittozzi, C., Sindoni, G., Paris, C., and del Marmo, P. P., "Application of an fbg sensors system for structural health monitoring and high performance trimming on racing yacht," in [Sensing Technology (ICST), 2011 Fifth International Conference on], 617-622 (Nov 2011).

[9] Sun, R.-j., Sun, L.-m., and Sun, Z., "Application of fbg sensing technologies to large bridge structural health monitoring," JOURNAL-TONGJI UNIVERSITY 36(2), 149 (2008).

[10] Moyo, P., Brownjohn, J., Suresh, R., and Tjin, S., "Development of fiber bragg grating sensors for monitoring civil infrastructure," Engineering structures 27(12), 1828-1834 (2005).

[11] Zhou, Z. and Ou, J., "Development of fbg sensors for structural health monitoring in civil infrastructures," in [Sensing issues in civil structural health monitoring], 197-207, Springer (2005).

[12] Todd, M., Johnson, G., Vohra, S., Chen-Chang, C., Danver, B., and Malsawma, L., "Civil infrastructure monitoring with fiber bragg grating sensor arrays," Structural Health Monitoring, 359-368 (1999).

[13] Davis, M. and Kersey, A., "Fiber bragg grating sensors for infrastructure sensing," in [Optical Fiber Communication. OFC 97., Conference on], 177-178, IEEE (1997).

[14] Majumder, M., Gangopadhyay, T. K., Chakraborty, A. K., Dasgupta, K., and Bhattacharya, D., "Fibre bragg gratings in structural health monitoringpresent status and applications," Sensors and Actuators A: Physical 147(1), 150 - 164 (2008).

[15] Vendittozzi, C., Felli, F., Brotzu, A., and Saviano, G., "Use of fbg sensors for the monitoring of cultural heritage, structures and monuments," in [Proceedings of the XXI IGF, Convegno Nazionale], 101-119 (2011).

[16] Felli, F., Paolozzi, A., Vendittozzi, C., and Paris, C., "Smart disaster mitigation in italy: A brief overview on the state of the art," in [ASME 2014 Conference on Smart Materials, Adaptive Structures and Intelligent Systems], V002T04A018, American Society of Mechanical Engineers (2014).

[17] Lupi, C., Felli, F., Caponero, M. A., and Paolozzi, A., "The effectiveness of metal coating on fbg sensor sensitivity at cryogenic temperature," (2007).

[18] Lupi, C., Felli, F., Ippoliti, L., Caponero, M. A., Fabbri, F., and Paolozzi, A., "Lead coating to improve fiber bragg grating sensitivity at cryogenic temperatures," (2005).

[19] Mendez, A., Turner, A., and Costantini, D., "Fbg optical sensing for pipeline structural health monitoring," in [8th Pipeline Technology Conference 2013], EITEP Institute (2013).

[20] Salazar-Ferro, A. and Mendez, A., "Oil pipeline geohazard monitoring using optical fiber fbg strain sensors (conference presentation)," (2016).

[21] Ren, L., guang Jia, Z., nan Li, H., and Song, G., "Design and experimental study on FBG hoop-strain sensor in pipeline monitoring," Optical Fiber Technology 20(1), 15 - 23 (2014).

[22] Ambastha, S., Umesh, S., and Sundarrajan, A., "Non-invasive pressure monitoring by hoop strain using fiber bragg grating sensor," (2015).

[23] Ren, L., Jia, Z., Ho, M. S. C., Yi, T., and Li, H., "Application of fiber bragg grating based strain sensor in pipeline vortex-induced vibration measurement," Science China Technological Sciences 57(9), 1714-1720 (2014).

[24] Leng, J.-c., Liu, Y., Zhou, G.-q., and Wu, Z.-m., "Pipeline stress monitoring method based on fiber bragg grating sensors," Pressure Vessel Technology 1, 011 (2013).

[25] Zhou, J., Sun, L., and Li, H., "Study on dynamic response measurement of the submarine pipeline by full-term fbg sensors," The Scientific World Journal 2014 (2014).

[26] Felli, F., Paolozzi, A., Vendittozzi, C., Paris, C., and Asanuma, H., "Use of fbg sensors for health monitoring of pipelines," (2016).

[27] Felli, F., Paolozzi, A., Vendittozzi, C., Paris, C., Asanuma, H., De Canio, G., Mongelli, M., and Colucci, A., "Structural health monitoring of pipelines for environment pollution mitigation," in [ASME 2015 Conference on Smart Materials, Adaptive Structures and Intelligent Systems], 2, V002T04A009- 7 pages, American Society of Mechanical Engineers (2015).

[28] Paolozzi, A., Felli, F., Vendittozzi, C., Paris, C., and Asanuma, H., "Analysis of fbg sensors data for pipeline monitoring," in [ASME 2016 Conference on Smart Materials, Adaptive Structures and Intelligent Systems], V001T04A012-V001T04A012, American Society of Mechanical Engineers (2016). 